\title{
Swiss Ball Training Verses Stable Surface Training on Functional Performance in Ambulatory Cerebral Palsy.
}

\author{
Dr Sumitra Sakhawalkar ${ }^{1,}$ Dr Sayli Paldhikar ${ }^{2}$ DrPriya Chitre ${ }^{3}$ \\ Dr Snehal Ghodey ${ }^{4}$ \\ ${ }^{1}$ Assistant Professor, Neurophysiotherapy Department / Maeers Physiotherapy College \\ ,Talegaondabhadepunemaharashtra.India. \\ ${ }^{2}$ Professor ,HODNeurophysiotherapy Department / Maeers Physiotherapy College , \\ Talegaondabhadepunemaharashtra.India. \\ ${ }^{3}$ Associate Professor, Neurophysiotherapy Department / Maeers Physiotherapy College \\ ,Talegaondabhadepunemaharashtra.India. \\ ${ }^{4}$ Principal ,Maeers Physiotherapy College, Talegaondabhadepunemaharashtra.India.
}

\begin{abstract}
The purpose of this study was to compare the effect of Swiss Ball training verses Stable surface training on Functional performance in ambulatory Cerebral Palsy.Institutional ethical committee permission was taken before starting the study. A sample of $73 \mathrm{CP}$ children were screened and 40 meeting the inclusion criteria were selected for study were then randomly divided into two groups one control other experimental i.e. 20 in each group by chit method. Both the groups were assessed with Pediatric Berg Balance Scale before and after the treatment. Control group were given Floor exercise and experimental group were be given Ball exercises for 10 repetition with 10 second hold, treatment time was 45 min per session with 3 days per week for 6 weeks. Both the groups were given the same sustained stretching technique for bilateral lower extremities for 10 repetition with 30 sec hold was given for, TA, Iliopsoas, Hamstrings, Adductors. Our study found that there was a similar effect of both Swiss Ball and Stable surface exercises on functional performance in ambulatoryCP. Significant improvement was noted in the intra group comparison of both the groups from baseline to post 6 week of intervention using PBBS.
\end{abstract}

Keywords:Swiss Ball, stable surface ( Floor), Cerebral palsy(CP), PBBS (Pediatric Berg Balance Scale), Functional performance.

\section{Introduction}

Cerebral palsy (CP) is a common developmental disability first described by William Little in the late $1840 \mathrm{~s}^{1}$.Sophie Levitt ${ }^{1}$ et al 1977 defined CP as an "umbrella term covering a group of non-progressive, but often changing, motor impairment syndromes secondary to lesions or anomalies of the immature brain arising in the early stages of its development", ${ }^{, 2,3}$. Prevalence of CP. is in the range of 2.5 to 3 per 1000 live births according to Indian paediatric society, while exact figures are unavailable in India ${ }^{4,5}$.

The pathological tone, in a CP kid may result in weakness, poor selective posture control and abnormal balance in standing ${ }^{1,3,4}$. The abnormal postures formed due to this tone are held by tight shorter spastic muscle groups whose antagonists are weak, and cannot overcome the tight pull of the spastic muscles and so cannot correct the abnormal postures ${ }^{1}$.Lack of isolated or discrete movements and fine motor coordination are also delayed with spastic type of ambulatory CP patients leading to poor trunk dissociation pattern of trunk with head and lower extremities ${ }^{8,9}$.

In cerebral palsied child it is often seen that the spastic muscles pull the limb into shortened position in the direction of their action causing deformities ${ }^{1,6}$. For example the tight spastic hip flexors lead to anterior pelvic tilt in turn causing the lumbar spine to go into hyper -lordosis and the weak gluteal are unable to prevent this as it would do so in normal individual. This lumbar hyper lordosis often causes a chain reaction in spinal alignment leading to lumbar extensor tightness and weak abdominals along with hip adductor and internal rotator tightness causing the child to crouch $^{7,8}$ leading to kinetic imbalance of weak abdominals and strong tight extensor of back leading to abnormal posture during weight bearing i.e. against gravity as in case of standing or walking. ${ }^{9,} 10$ The postural muscles that help in maintaining spinal alignment are also commonly called the core $^{11,12}$.Bergmark ${ }^{13}$ divided the trunk core muscles into "global" and "local" groups, based on their primary roles in maintainance of spinal stability during weight bearing. Also described by Wilderson in his model of core stability. ${ }^{13}$ 


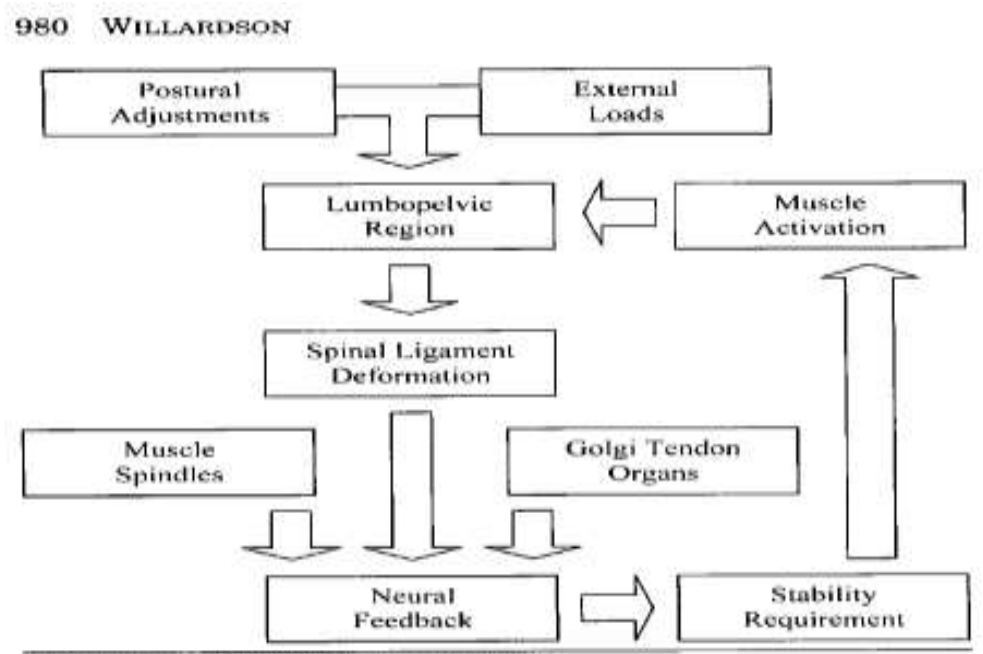

Fraurede 1. Model of core stability.

In Spastic CP, Floor exercises for back extensors and abdominals were traditionally given with a stable and large base of support. They are effective in training the core muscles ${ }^{14,15}$. Later on, Swiss Balls (Bobath Ball) came into picture as an effective aid for exercises in 1963. Quinton ${ }^{16,17}$, in 1970, for the first time, used toy stability Balls for rehabilitation of children with neurological impairments. Ball can be used to give functional training in muscles for eccentric and concentric hold simultaneously along with activation of postural mechanisms which cannot be achieved efficiently in Floor exercises. Lateral control and diagonal patterns can be facilitated ${ }^{18}$.

Ball exercises enables the use of techniques of muscle elongation, joint mobility in all these patterns mentioned above for activation and strengthening of abdominals and back extensors that can help the child to achieve co -contraction of agonist antagonist and activate reciprocal inhibition making spinal alignment stable but not rigid there by allowing the child to gain postural control against gravity in standing and walking $15,17$. The functional performance of the CP child was hence analysed by using Paediatric Berg Balance Scale. ${ }^{18}$

- The Aim of this study was to compare the effect ofSwiss Ball training verses Stable surface training on Functional performance in ambulatory Cerebral Palsy.The objective of this study was :

- To determine the effect of Swiss Ball training on Functional performance in ambulatory Cerebral Palsy.

- To determine the effect of Stable surface training on Functional performance in ambulatory Cerebral Palsy.

- To compare the effect of Swiss Ball training verses Stable surface training on Functional performance in ambulatory Cerebral Palsy.

- To measure the functional performance by using Pediatric berg balance scale.( PBBS)

\section{Materials AndMethod}

This was a experimental study, a Randomised Clinical Trial, sample of 40 divided into 20 each group i.e control and experimental byRandomised Purposive sampling Technique.Study set up was Neuro physiotherapy O.P.D in Rural hospital and CP school in Rural areas.

\section{Criteria of study:}

- Inclusion criteria: 1.All ambulatory cerebral palsy patients( with or without Ambulatory aid /Orthosis) according to SAAROM (The spine alignment and range of motion measure scale(grade 0 to grade 2$)^{19}$

2. Age 3 to 16 yrs old ${ }^{2}$

3. Mini-mental state examination score $\geq 24$ (cognition\& perception deficit $)^{20}$

- Exclusion criteria :Cerebral palsy patients with MR and cognitive, perception dysfunction Materials Used: 1 .Swiss Ball of ( $45-65 \mathrm{cms})$, 2. Floor mat, 3. PBBS scale 4.pen 5.Paper

\section{Procedure}

The sample 73 was screened, of which 40 meeting the inclusion criteria were selected. This sample of 40 was then randomly divided into two groups one control other experimental i.e. 20 in each group by chit method.Demographic data and basic Neurological examination was done. Both the groups were assessed with : Pediatric Berg Balance Scale, ${ }^{18}$ before and after the treatment. Both the groups i.e. control and experimental were given the same sustained stretching technique for bilateral lower extremities for 10 repetition with $30 \mathrm{sec}$ 
hold was given for , TA , Iliopsoas ,Hamstrings ,Adductors. . Control group were given stable surface ieFloor exercise and experimental group were be given Ball exercises were given in Supine Prone And Side lying positions for 10 repetition with 10 second hold, treatment time was 45 min per session with 3days per week for 6 weeks. $^{13,14,15}$

Some of the exercises of control group were :Curl ups ,diagonal curl ups, bridging, prone on palms quadripod position, bird dog position, prone hip extension.$^{13,14}$
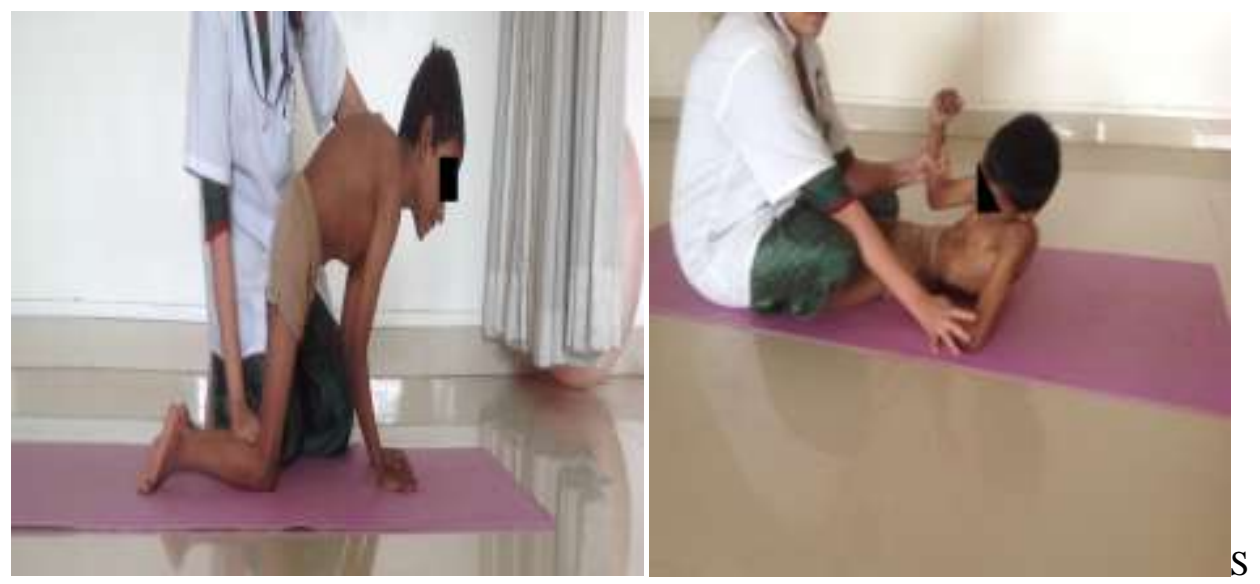

Some of the ball exercises given were : Curl ups and diagonal Curl ups and bridging on Swiss Ball . Runners position, prone on palms prone hip Extension, Thoracolumbar HyperExtension, Lenthening of Latissmuss Dorsi and Quadratus Lumborum .
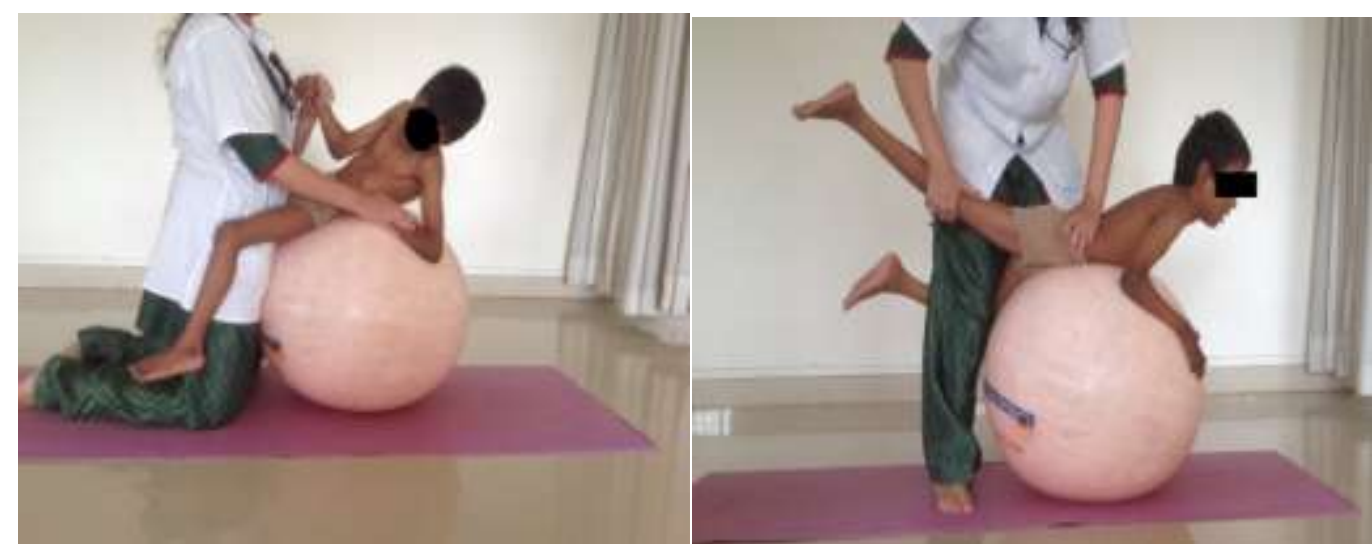

\section{Results}

The data on qualitative characteristics (such as sex, age group etc) is presented as $\mathrm{n}$ (\% of cases). The data on quantitative characteristics (such as PBBS, ) is presented as Mean \pm Standard error of mean (SEM) across two study groups. The statistical significance of difference of qualitative characteristics across two study groups is tested using Chi-Square test. The assumption of normality of the given data in the present study was tested using theShapiro Wilk's test. The statistical significance of inter-group difference of mean of quantitative characteristics is tested using unpaired ' $t$ ' test, after confirming the underlying normality assumption. The statistical significance of intra-group difference of mean of quantitative characteristics is tested using paired' $t$ ' test, after confirming the underlying normality assumption of difference of baseline and posttreatment parameters in each study group.

\begin{tabular}{|c|c|c|c|c|}
\hline \multicolumn{2}{|c|}{ PBBS } & $\begin{array}{c}\text { Control Group } \\
(\mathbf{n}=20)\end{array}$ & $\begin{array}{c}\text { Experimental } \\
\text { Group (n=20) }\end{array}$ & $\begin{array}{c}\text { P-value } \\
\text { [Inter-Group] }\end{array}$ \\
\hline PBBS & Baseline & $35.5 \pm 1.98$ & $34.7 \pm 2.10$ & $0.784^{\text {NS }}$ \\
& 6-Weeks & $42.4 \pm 1.91$ & $42.3 \pm 1.91$ & $0.985^{\text {NS }}$ \\
& \% Change & $21.1 \%$ & $24.5 \%$ & $0.322^{\text {NS }}$ \\
\hline $\begin{array}{c}\text { P-value [Intra- } \\
\text { Group] }\end{array}$ & Baseline v 6- & $0.001^{* * * *}$ & $0.001^{* * * *}$ & -- \\
\hline
\end{tabular}

Table 1) The intra-group and inter-group comparison of Paediatric berg balance score (PBBS) across two study groups. Values are mean \pm standard error of mean. P-values for inter-group comparisons by unpaired $t$ 
test. P-values for intra-group comparisons by paired $\mathrm{t}$ test. $\mathrm{P}$-value $<0.05$ is considered to be statistically significant. $* \mathrm{P}$-value $<0.05$, $* * \mathrm{P}$-value $<0.01, * * * \mathrm{P}$-value $<0.001$, NS: Statistically Non-Significant.

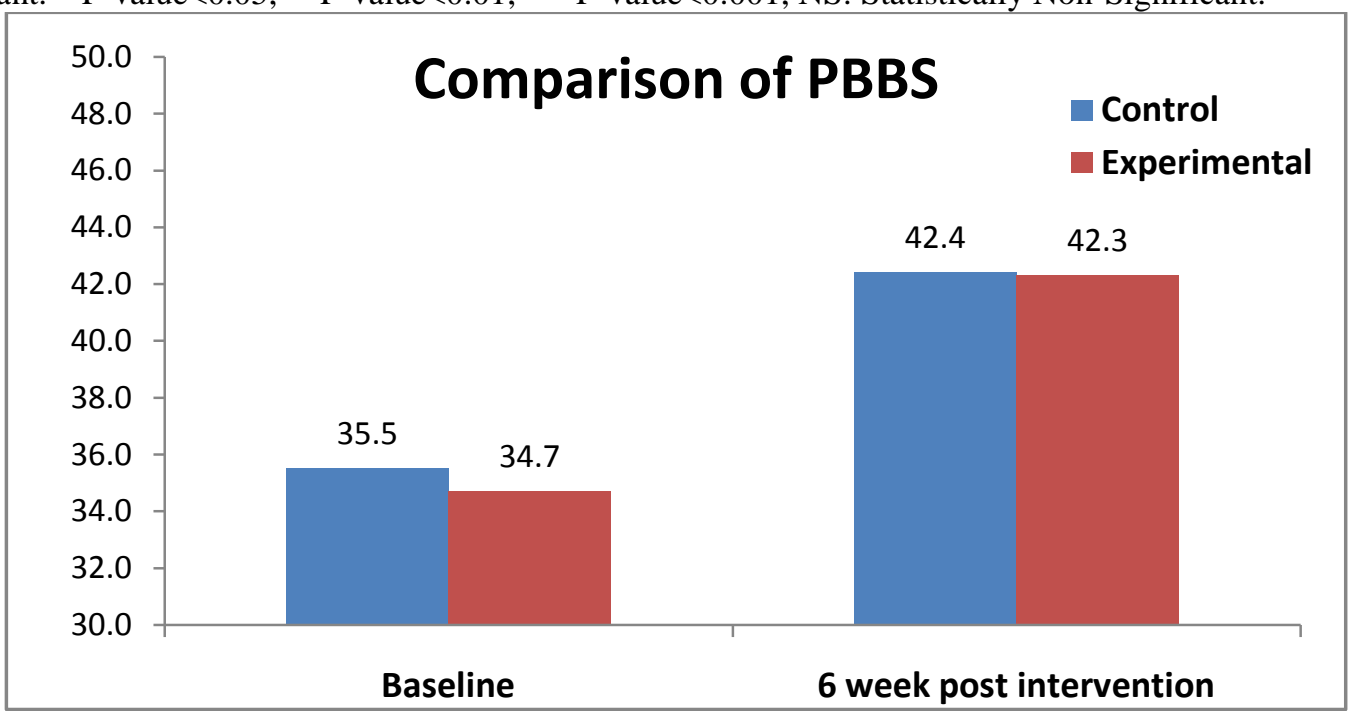

Figure 1) The intra-group and inter-group distribution of Paediatric berg balance score (PBBS) across two study groups.

1) Inter Group comparisons:

a. The mean baseline PBBS score did not differ significantly between control and experimental groups (Pvalue $>0.05$ ).

b. The mean 6-weeks post-treatment PBBS score did not differ significantly between control and experimental groups (P-value>0.05).

c. The mean 6-weeks post-treatment \% change in PBBS score did not differ significantly between control and experimental groups (P-value $>0.05)$.

2) Intra Group comparisons:

a. The mean 6-weeks post-treatment PBBS score is significantly higher compared to the baseline PBBS score in Control group ( $\mathrm{P}$-value $<0.001)$.

b. The mean 6-weeks post-treatment PBBS score is significantly higher compared to the baseline PBBS score in Experimental group (P-value<0.001).

\section{Discussion}

The study was designed to compare the effect of Swiss Ball training verses Stable surface training on Functional performance in ambulatory Cerebral Palsy. The sample 73 was screened, of which 40 meeting the inclusion criteria were selected. This sample of 40 was then randomly divided into two groups one control other experimental i.e. 20 in each group by chit method.. Both the groups were assessed with : Pediatric Berg Balance Scale, ${ }^{28}$ before and after the treatment. Both the groups i.e. control and experimental were given the same sustained stretching technique for bilateral lower extremities for 10 repetition with $30 \mathrm{sec}$ hold was given for , TA , Iliopsoas ,Hamstrings ,Adductors. . Control group were given stable surface ie floor exercise and experimental group were be given Ball exercises were given in Supine Prone And Side lying positions for 10 repetition with 10 second hold, treatment time was 45 min per session with 3days per week for 6 weeks.

Based on the Statistical analysis mentioned in the Results above, Our study found that there was a similar effect of both Swiss Ball and Stable surface exercises on functional performance in ambulatory cerebral palsy. Significant improvement was noted in the intra group comparison of both the groups from baseline to post 6 week of intervention following domains of PBBS ( table no 1) like :

1. sit to stand and stand to sit,

2. turning to look behind,

3. retrieving object from Floor,

4. placing alternate foot on the stool,

5. standing upright,

6. sitting unsupported,

7. reaching forward with an outstretched arm,

8. standing with feet together,

9. placing one foot in front of other foot,

10. Standing on one leg. 
This improvement in the above mentioned outcome measures can be attributed to strengthening of Abdominals ,Trunk extensors and lateral flexors ,Hip and Pelvic musculature given by Stable surface exercises in control group and Ball exercises in the experimental group .Exercises like Curl Ups and Diagonal Curl ups given both on Floor and Ball targeted to facilitate trunk flexors. Curl ups given to the child activated abdominal musculature by actively flexing the trunk through concentric muscle action, isometric contractions during the hold portion, and eccentric muscle actions during the return to the starting position ${ }^{13,15}$. Studies showed that the traditional curl-up and Ball exercise is able to generate more activation of the rectus abdominis muscle, when compared to other exercises to strengthen the abdominal muscles. The rectus abdominismuscle is responsible for the first $30^{\circ}$ to $45^{\circ}$ of trunk flexion. Escamilla ${ }^{21}$ et al 2006.found a 50\% activation of the rectus abdominis and $16 \%$ for the external oblique and Konrad et al.2010 found an activation of $51 \%$ for the rectus abdominis and $28 \%$ for the external oblique $22,23,24$

Curl ups done on Ball provides spinal stabilization by fixing upper or lower trunk during exercise, and allowing gravity to distract the spine by passive lengthening of the spinal attachments from the point of stability ${ }^{13,15}$. Garry T. Allison ${ }^{25}$ et al in 2008 explored the role of deeper abdominal muscles (e.g., transversus abdominis and internal oblique) in enhancing spinal and pelvic stabilization and increasing intra-abdominal pressure during trunk stability exercises ${ }^{66}$. Intra-abdominal pressure has been shown to unload the spine by generating a trunk extensor moment and tensile loading to the spine. As the trunk becomes a more solid cylinder by the intra-abdominal pressure mechanism, there is a reduction in spinal axial compression and shear loads ${ }^{15,25}$.The attachments of the transversus abdominis and internal oblique into the thoracolumbar fascia may enhance spinal and pelvic stabilization, because when these muscles contract they tense the thoracolumbar fascia. The transversus abdominis has been shown to exhibit a similar muscle activation pattern and amplitude as the internal oblique during abdominal exercises even during the initial phase of curl up (within $15 \%)^{25}$. The findings of our study are consistent with many studies in literature done on $\mathrm{CP}$ population as well normal individuals ${ }^{26,27,28,29}$.

Prone development which activates head and back extension is frequently poor in cerebral palsy child. According to the Bobaths ${ }^{1}$ this position of child first forms a reflex inhibiting posture for flexor tone in lower limb muscles and allows the pelvis to be stabilized ${ }^{13,14,15}$. During the prone exercises, like prone on elbows and palms, exercises performed on Ball as well as on Floors, improves the stabilization of hip and shoulder. Elongation of abdominal, mainly rectus abdominals , oblique's , transverses abdominals, ilio psoas , latissimus dorsi, facilitates the spinal extension. Isometric actions of rectus abdominis and oblique, along with concentric actions of the spinal extensors such as erector spinae, quadratus lumborum with co-activation of hip extensors counteract the forces of gravity to extend the trunk and maintain the pelvis in neutral. ${ }^{30,31}$

It may be argued that the increase in activation levels of the external oblique and the rectus abdominals during prone bridging appear to be caused by decreases in surface stability and not different biomechanical demands due to the body's position relative to gravity. While there were differences in the body's position relative to gravity between the ground exercise and the Ball exercise during prone and supine bridging, finds the participant in a more vertical position. This suggests there is less force creating a trunk extension movement (i.e. gravity attempts to increase lordosis which is resisted by muscle activity) due to the fact that the Centre of mass of the trunk and head segment would be closer to the axis for trunk extension. Therefore less muscle activity may have been generated to resist this torque (compared with the ground based bridge) and more muscle activity may have been required to produce secondary spinal stabilization due to the labile surface ${ }^{32}$.

This exercise may have improved functional performance of the child in PBBS task when the child could perform turning to look behind from either side while maintaining lower limbs in upright position, also during standing with one foot placed in front of the other, sit to stand and vice versa more efficiently. Wide BOS, low COG maybe one of the factor why the child could easily perform this exercise with ease ${ }^{15}$. Also another study done by Mori $\mathbf{A}^{\mathbf{3 3}}$ et al withElectromyographic activity of selected trunk muscles during stabilization exercises using a gym Ball. The results of this study demonstrated, Lifting up of the pelvis in a bridged position exercise, supporting the head with the gym Ball and with the feet on the Floor in supine position, resulted in higher muscle activity of the back extensor muscles than another exercise. ${ }^{33}$

Quadratus Lumborum works synergistically to latissimus dorsi, abdominals to gain lateral trunk contro $^{15}$. Swiss Ball exercises also facilitates trunk rotation with hip extension and abduction and thereby helping the child to maintain spine alignment of trunk with respect to pelvis during trunk dissociation. During lateral flexion if the child goes into hyperextension of spine then both latissimus dorsi and quadratus lumborum act as a strong stabilizer of spine .causing anterior tilting of pelvis and hence lengthening of these muscles is a must which was achieved in our study ${ }^{13,15}$. The result of functional improvement was seen while performing PBBS task like placing alternate foot on stool and one leg stand, turning to look behind from either side, reaching forward with an outstretched arm.McGill stated, "The relative contributions of each muscle continually changes throughout a task, such that discussion of the most important stabilizing muscle is restricted to a 
transient instant in time.Cholewicki and Van Vliet ,in 1997 who investigated the relative contribution of core muscles to lumbar spine stability, reported that no single core muscle can be identified as most important for lumbar spine stability. Moreover, the relative contribution of each core muscle to lumbar spine stability depends on trunk loading direction and magnitude in all types to trunk stabilization exercises given to enhance trunk control and improve spinal alignment ${ }^{37,38}$.

\section{Conclusion}

From the results of our study we conclude that :

- Both Swiss Ball Training as well as Stable surface Training are equally effective in improving the functional performance as measured by Paediatric Berg Balance Scale in ambulatory cerebral palsy from baseline to post 6 week of intervention.

\section{Limitations}

There were a few limitations observed throughout the study conducted .

They are:

- A smaller sample size therefore the study cannot be generalised to the $\mathrm{CP}$ population .

- Electromyographic Recording of core muscles could be recorded to determine the activation of trunk muscles during these intervention in cerebral palsy children ..

\section{Clinical Implication}

As both Swiss Ball exercises and Stable surface exercises are equally effective in improving the functional performance in ambulatory cerebral palsy patients. Either of them can be used to get the same extent of improvement in functional performance of the child and his spinal alignment. This would be immensely helpful in rural areas or remote areas where Swiss Ball is not readily available. The important aspect being any form of intervention is necessary for a $\mathrm{CP}$ child than no intervention at all. This is most predominantly noted in the rural areas of our country where any equipment or regular treatment is not given to a child by the family .These interventions can improve the child's functional performance and make him independent in doing daily activities.

\section{Reffernces}

[1]. Sophie Levitt : Treatmenent of Cerebral Palsy and Motor Delay,Fourth edition published

[2]. by Blackwell Publishing 2004

[3]. Shumway cookandwoolacolt : MOTOR CONTROL AND LEARNING $3^{\text {rd }}$ edition

[4]. Copyright @ 2007 ,Lippincott Williams \& Wilkins , a Wolters ,Kluwer business

[5]. ISBN13 : 978-07817-6691-3 ; ISBN10 : 07817-6691-5

[6]. Mark L. Latash\&FrancisLestienne : MOTOR CONTROL AND LEARNING 2006

[7]. Springer Science +Business Media, Inc.

[8]. T.K. Banerjee, et al...." Neurological disorders in children and Adolescents"

[9]. Indian journal of paediatrics vol76, no 2pp 139-146 2009.

[10]. ChitraSankar, NandaniMundankar: Cerebral palsy : Definition, Classification, Aetiology

[11]. and early diagnosis .Indian Journal Of Paediatrics 2005 72(10) : 865868.

[12]. Freemanmiller : Physical therapy of cerebral palsy@ 2007 Springer Science +Business

[13]. Media, Inc.

[14]. NadireBERKERSelim YALÇIN : The HELP Guide To Cerebral Palsy Second Edition

[15]. 2010, ISBN: 978-1-60189-102-0No: 8 in PediatricOrthopedics\& Rehabilitation Series

[16]. Printed at: Merrill Corporation.

[17]. Barbara H. Connolly, Patricia C. Montgomery.: Therapeutic exercise in

[18]. developmentaldisabilities 3rd edition Copyright (C) 2005 by SLACK Incorporated

[19]. ARCHIE HINCHCLIFFE, Illustrations by Barbara Lynne Price and Clare Rogers

[20]. Children with cerebral palsy: A manual for therapists, parents and community workers.

[21]. 2nd edition published in 2007 by Sage Publications India Pvt Ltd $\$

[22]. White and Punjabi : Biomechanics of spine 2ndedition ISBN 0-397-507208 1990 ,J.B. Lippincott Company

[23]. CAROL OATIS : KINESIOLOGY : The path mechanics and normal mechanics of

[24]. human movement $2^{\text {nd }}$ edition Copyright (C) 2009, 2004 Lippincott Williams \& Wilkins,

[25]. a Wolters ,Kluwer business

[26]. JEFFREY M. WILLARDSON : CORE STABILITY TRAINING: APPLICATIONS To SPORTS CONDITIONING PROGRAMS Journal of Strength and Conditioning Research,2007, 21(3), 979-985 (C) 2007 National Strength \& Conditioning Association Cross ref : Aeta Orthopaedic . :Scand. 230(Suppl.):20-24. 1989 ,J. Spinal Disorder. 5:390-397. 1992.

[27]. Kissner and Colby : Therapeutic exercise Foundation and techniques 6th edition

[28]. Copyright (C) 2011 by F. A. Davis Company

[29]. Hall and broody : Therapeutics Exercises $2^{\text {nd }}$ edition 2007 Lippincott Williams

[30]. Barbara hypes PT : Facilitating development and sensorimotor function treatment

[31]. with ball. 1991 by PDP press , Inc. ISBN NO : 0-9623703-3-9

[32]. Sue Rayne, Linzi Meadows, Mary Lynch-Ellerington :Bobath Concept Theory and Clinical Practice inNeurological Rehabilitation. (C) 2009 by Blackwell Publishing Ltd

[33]. Cynthia norkins : Joint structure and Function Section 5 chapter $13,5^{\text {th }}$ edition Copyright (C) 2011 by F. A. Davis Company 
[34]. Yi SH ${ }^{1}$, Hwang JH, Kim SJ, Kwon JY. Validity of pediatric balance scales in children with spastic cerebral palsy .Neuropediatrics. 2012 Dec;43(6):307-13. doi: 10.1055/s-0032-1327774. Epub 2012 Sep 25

[35]. Chia-Ling Chen1,2 | Katie P H Wu1 | Wen-Yu Liu3 | Hsin-Yi Kathy Cheng2 | I-Hsuan Shen4 |Keh-Chung LiValidity and clinimetric properties of the Spinal Alignment and Range of Motion Measure in children with cerebral palsy. Developmental Medicine \& Child Neurology april 2013, 55: 745-750

[36]. Susan O' Sullivan; Raymond SiegelmanPT EXAM : Exercise Principles And Guidelines For Persons With Cerebral Palsy And Neuromuscular Disorders National Physical Therapy examination review \& Study Guide 2011 the complete Study Guide; Scott M, Gill IQ Physical and Occupational Therapy Reviewe McGraw-Hills NPTE; Mark Dutton

[37]. Escamilla RF, McTaggart MS, Fricklas EJ, et al. An electromyographic analysis of commercial and common abdominal xercises: implications for rehabilitation and training. J OrthopSports Phys Ther.2006; 36:4557.http://dx.doi.org/10.2519/jospt.2006.2054

[38]. Escamilla RF, Lewis C, Bell D, Bramblet G, Daffron J, Lambert S et al. Core muscle activation during swiss ball and traditional abdominal exercises. J Orthop Sports Phys Ther 2010;40:265-76.

[39]. Juker D, McGill S, Kropf P, Steffen T. Quantitative intramuscular myoelectric activity of lumbar portions of psoas and the abdominal wall during a wide variety of tasks. Med Sci Sports Exercise 1998; 30:301-310.

[40]. McGill S, Juker D, Kropf P. Appropriately placed surface EMG electrodes reflect deep muscle activity (psoas, quadratus lumborum, abdominal wall) in the lumbar spine. J Biomech. 1996;29:1503-1507.

[41]. GARRY T. ALLISON, SUE L. MORRIS, Feedforward Responses of Transversus Abdominis Are Directionally Specific and Act Asymmetrically: Implications for Core Stability Theories. may $2008 \mid$ volume $38 \mid$ number 5 journal of orthopaedic \&sports physical therapy:Crossrefer:Scand J Rehabil Med. 1994;26:79-86 ; ActaPhysiol Scand. 1992;144:409-418.

[42]. El-Basatiny HMY, Abdel-aziem AA. Effect of Trunk Exercises on Trunk control, Balance and Mobility Function in Children with Hemiparetic Cerebral Palsy. IJTRR. 2015; 4(5): 236-243. doi:10.5455/ijtrr.00000094

[43]. Beim GM, Giraldo JL, Pincivero DM, Borror MJ, Fu FH. Abdominal strengthening exercises: a comparative EMG study. J Sport Rehab. 1997;6:11-20.

[44]. Escamilla RF, Babb E, DeWitt R, et al. Electromyographic analysis of traditional and nontraditional abdominal exercises: implications for rehabilitation and training. Phys Ther. 2006;86:656-671.

[45]. Escamilla RF, McTaggart MS, Fricklas EJ, et al. An electromyographic analysis of commercial and common abdominal exercises: implications for rehabilitation and training. J OrthopSports Phys Ther. 2006;36:45-57. http://dx.doi.org/10.2519/jospt.2006.2054

[46]. Freeman S, Karpowicz A, Gray J, McGill S. Quantifying muscle patterns and spine load during various forms of the push-up. Med SciSportsExerc. 2006;38:570-577. http://dx.doi.org/10.1249/01.mss.0000189317.08635.1b

[47]. Grenier SG, McGill SM. Quantification of lumbar stability by using 2 different abdominal activation strategies. Arch Phys Med Rehabil. 2007;88:54-62. http://dx.doi.org/10.1016/j.apmr.2006.10.014

[48]. Gregory J Lehman, ${ }^{1}{ }^{1}$ Wajid Hoda, ${ }^{1}$ and Steven OliverTrunkmuscle activity during bridging exercises on and off a Swissball PMCID: PMC1187901

[49]. Phys Ther Sport 2009;10:57-62.

[50]. Mori AElectromyographic activity of selected trunk muscles during stabilization exercises using a gym ball ${ }^{1}$. ElectromyogrClinNeurophysiol. 2004 Jan-Feb;44(1):57-64.

[51]. Behm DG ${ }^{1}$, Leonard AM, Young WB, Bonsey WA, MacKinnon SN. : Trunk muscle electromyographic activity with unstable and unilateral exercises.J Strength Cond Res. 2005Feb;19(1):193-201.

[52]. Rogan $\mathbf{S}^{\mathbf{1}}$, Riesen $\mathbf{J}^{\mathbf{2}}$, Taeymans J].Praxis (Bern 1994). [Core muscle chains activation during core exercises determined by EMGa systematic review 2014 Oct 15;103(21):1263-70. doi: 10.1024/1661-8157/a001803.

[53]. McGill SM, Grenier S, Kavcic N, Cholewicki J. Coordination of muscle activity to assure stability of the lumbar spine. J ElectromyogrKinesiol. 2003;13:353-359.

[54]. Axler CT, McGill SM. Low back loads over a variety of abdominal exercises: searching for the safest abdominal challenge. Med Sci Sports Exerc. 1997;29:804-811

[55]. Cholewicki J , VanVlietJJt. Relative contribution of trunk muscles to the stability of the lumbar spine during isometric exertions. ClinBiomech (Bristol, Avon). 2002;17:99-105. 